\title{
Acroosteolysis in systemic sclerosis: An insight into hypoxia-related pathogenesis (Review)
}

\author{
SIMON SIAO-PIN $^{1,2}$, LAURA-OTILIA DAMIAN ${ }^{2}$, LAURA MIRELA MUNTEAN ${ }^{1,2}$ and SIMONA REDNIC ${ }^{1,2}$ \\ ${ }^{1}$ Rheumatology Department, 'Iuliu Hațieganu' University of Medicine and Pharmacy Cluj, 400012 Cluj-Napoca; \\ ${ }^{2}$ Rheumatology Department, Emergency Clinical County Hospital Cluj, 400006 Cluj-Napoca, Romania
}

Received April 20,2016; Accepted July 1, 2016

DOI: $10.3892 /$ etm.2016.3782

\begin{abstract}
Acro-osteolysis, or bony resorption of the terminal digital tufts, is a well-recognized, but under-researched, feature of systemic sclerosis. The mechanisms that disturbs local homeostatic balance of bone formation and resorption in favor of osteoclast activation and pathological bone loss remain to be established. Vascular alterations and reduced capillary density impair tissue oxygenation in systemic sclerosis, and the resulting hypoxia might contribute directly to the disease progression. In this paper we summarize the current evidence for hypoxia as the common pathophysiological denominator of digital vasculopathy and enhanced osteoclastic activity in systemic sclerosis-associated acroosteolysis. The hypoxia-inducible transcription factor HIF-1 $\alpha$ and VEGF signaling has a critical role in regulating osteoclastic bone-resorption and angiogenesis, and increased osteoclastogenesis and higher VEGF levels may contribute to acroosteolysis in systemic sclerosis. The cells of the osteoblast lineage also have important roles in angiogenic-osteogenic coupling. The research in this field might help limiting the disability associated with the disease.
\end{abstract}

\section{Contents}

1. Introduction

2. Hypoxia in systemic sclerosis: The HIF pathway and its dysregulation in angiogenesis and osteoclastogenesis

3. Conclusions

Correspondence to: Dr Laura-Otilia Damian, Rheumatology Department, Emergency Clinical County Hospital Cluj, 2-4 Clinicilor Street, 400006 Cluj-Napoca, Romania

E-mail: lauradamiancj@yahoo.com

Abbreviations: AO, acroosteolysis; Ang, angiopoietin; ANGPTL, angiopoietin-like protein; BMP, bone morphogenetic protein; CTGF, connective tissue growth factor; HIF- $\alpha$, hypoxia-inducible factor $\alpha$; NVC, nailfold videocapillaroscopy; SSc, systemic sclerosis; VEGF, vascular endothelial growth factor

Key words: acroosteolysis, systemic sclerosis, hypoxia, angiogenesis, VEGF, bone cells

\section{Introduction}

Systemic sclerosis (SSc) is an autoimmune disease characterized by microvascular impairment, immune dysregulation and fibrosis (1). Acroosteolysis (AO), a distinct pattern of bone resorption affecting the distal portion of the fingers, which occurs in $6-65 \%$ of patients with SSc, is an incompletely addressed feature of the disease that contributes to disability and pain (2-6).

AO is very suggestive of SSc, although not pathognomonic, being encountered in several congenital or acquired entities (7). The clinical and radiographic course of SSc-related AO is variable, as stabilization of osteolysis can occur in some patients, while in others, osteolysis progresses towards complete loss of distal phalanges and even to digital telescoping. Osteolysis generally starts on the palmar aspect of the tuft, leading to sharpening of the distal phalanx and, in rare cases, the middle phalanx (5). Ultrasonography is similar to radiography in the detection of $\mathrm{AO}$, revealing interruption of the cortical contours and increased vascularization at bone resorption sites (8). Rarely resorption may affect other bones, such as the mandible, distal radius and ulna, distal clavicle, ribs or even cervical vertebrae (9). It is not clear whether AO occurs preferentially within the limited form of disease (4). However, AO has been suggested to be associated with the duration of disease, digital ulcers, severe digital ischemia, severe Raynaud's phenomenon, late capillaroscopic pattern with severe capillary loss, pulmonary arterial hypertension, hand calcinosis, secondary hyperparathyroidism and in general with more severe disease $(2,4)$.

The pathogenesis of AO in SSc is not well understood; presumed mechanisms include a reduction of vascular supply due to digital occlusive vasculopathy and later due to external compression from skin tightening, impaired angiogenesis due to defective sprouting following hand microtrauma, nerve alteration due to compressive neuropathy in the carpal, ulnar or cubital tunnel, and occult hyperparathyroidism resulting from vitamin D deficiency (7-10). However, the main contributors to AO in SSc appear to be vascular impairment, as well as an imbalance in bone remodeling favoring resorption. Bone homeostasis requires an adequate vascular supply, and a close spatial-temporal association exists between angiogenesis and osteogenesis during skeletal development, bone growth and fracture healing (11). Angiogenesis is a crucial component of 
bone remodeling. While tissue hypoxia normally stimulates angiogenesis, SSc is characterized by a decreased and inefficient angiogenic response, leading to a failure to replace damaged vessels and a reduction of capillary density (12). The present review addresses the hypothesis that hypoxia and chronic ischemia-derived stimuli are involved in the development and progression of SSc-associated AO.

\section{Hypoxia in systemic sclerosis: The HIF pathway and its dysregulation in angiogenesis and osteoclastogenesis}

In SSc chronic tissue hypoxia results from obliterative vasculopathy, reduced capillary density and the overproduction of extracellular matrix proteins causing impairment of diffusion from blood vessels to cells (12). The master transcriptional regulator of the adaptive response to hypoxia is hypoxia-inducible factor- $1 \alpha$ (HIF-1 $\alpha)(13)$. HIF-1 $\alpha$ negative regulators are HIF prolyl hydroxylases (PHDs) and Von Hippel-Lindau tumor suppressor protein (14). Hypoxia promotes the increase of HIF-1 $\alpha$ in virtually all cell types; in normoxia, HIF-1 $\alpha$ is rapidly destroyed following hydroxylation by PHDs, whereas during hypoxia, prolylhydroxylation is blocked, leading to HIF- $1 \alpha$ stabilization, nuclear translocation and gene activation (13). The HIF pathways regulate pro-angiogenic genes, including vascular endothelial growth factor (VEGF), angiopoietin (Ang)-1 and Ang-2, platelet-derived growth factor (PDGF), basic fibroblast growth factor and monocyte chemoattractant protein-1 (15). Therefore, HIF-1 is a global mediator of the angiogenic response to hypoxia.

Vascular perspective. Vascular homeostasis depends on the balance of at least two main systems: VEGF/VEGF receptor (VEGFR) and the Ang-Tie ligand-receptor system. Numerous other factors are involved, including endostatin, angiostatin, PDGF and fibroblast growth factor-2.

$V E G F / V E G F$ receptor system. VEGF, one of the main transcriptional targets of HIF-1 $\alpha$, is the primary cytokine associated with angiogenesis. In addition to HIF-1 $\alpha$ and chronic hypoxia, other inducers of VEGF in SSc are interleukin-1 $\beta$, PDGF and transforming growth factor (TGF)- $\beta$ (16). The VEGF family includes VEGF-A, -B, -C and -D and placenta growth factor. VEGF-A (usually referred to as VEGF) is released by fibroblasts, macrophages, endothelial cells and $\mathrm{T}$ cells and is involved in angiogenesis at many levels (17). The effects of VEGF are regulated by its three tyrosine kinase receptors (VEGFR-1/Flt-1, VEGFR-2/Flk-1 and VEGFR-3). VEGFR-2/Flk-1 is required for the mitotic response of endothelial cells to VEGF (18). Endostatin is the most potent inhibitor of VEGF-induced angiogenesis (17).

$\mathrm{AO}$ in SSc is associated with increased osteoclastogenesis and higher VEGF levels $(19,20)$. In patients with SSc the proangiogenic VEGF-A and its receptors are paradoxically overexpressed despite insufficient angiogenesis, correlating with disease progression and fingertip ulcer development $(19,20)$. An explanation could be the overexpression of VEGF 165b, an inhibitory splice variant of VEGF leading to insufficient angiogenesis; in patients with SSc, VEGF165b correlates with the extent of videocapillaroscopic damage and loss (21). The typical capillaroscopic changes in
SSc have been interpreted as failed angiogenic attempts following VEGF stimulation, resulting in a disturbed capillary network (19).

Ang-Tie pathway. The Ang-Tie ligand-receptor system is important in the regulation of vascular integrity and quiescence. The constitutive Ang-1/Tie2 interaction is the default vascular homeostasis control pathway, while Ang-2 acts as a dynamically regulated vessel-destabilizing cytokine (22).

The Ang-Tie ligand-receptor comprises two receptor kinases, Tie1 and Tie2, and four corresponding ligands, Ang-1, $-2,-3$ and -4 (23). Ang-1 inhibits VEGF-induced formation of blood vessels, the expression of adhesion molecules and TNF- $\alpha$-stimulated leukocyte transmigration (22). Ang-2, a Tie2 antagonist, which is almost undetectable in endothelium at rest, is rapidly induced during activation, resulting in endothelial destabilization required for angiogenesis and/or inflammation in the presence of VEGF, while in the absence of VEGF Ang-2 causes vascular regression (24). Ang-1 is significantly decreased while serum Ang-2 is substantially elevated in SSc, particularly in patients with a 'late' nailfold videocapillaroscopy pattern, correlating with erythrocyte sedimentation rate and C-reactive protein levels, and lung involvement (25). The Ang-1/Ang-2 imbalance in patients with SSc suggests a shift toward vascular regression and angiostasis (26).

Bone perspective. Bone remodeling is a dynamic process that requires functional coordination between osteoclasts, osteoblasts and osteocytes. In SSc the generalized prevalence of osteoporosis appears to be increased, involving several humoral and cellular players $(4,9)$.

Angiopoietin-like proteins. Angiopoietin-like proteins (ANGPTLs) are a family of proteins with structural similarities to the angiopoietins, which do not bind to Tie receptors, and have roles in lipid and glucose metabolism, inflammation, hematopoiesis and cancer (27). Of these, ANGPTL4, regulated by HIF- $1 \alpha$, is able to stimulate osteoclasts even when HIF- $1 \alpha$ is deficient (28). Its N-terminal fragment inhibits angiogenesis, while the C-terminal fragment modulates cell adhesion. ANGTL4 is overexpressed in the osteoclasts, synovial cells, synovial fluid and serum of patients with rheumatoid arthritis (RA), suggesting its involvement in RA erosions (29). Although arthritis is an independent predictive factor for disease progression in patients with early SSc. it seems unlikely that SSc-associated AO is due to synovial ANGPTL4 over-expression driving osteoclast-mediated bone resorption, as $\mathrm{AO}$ is associated with vascular involvement rather than synovitis $(2,29)$. To date, there are no studies in which the ANGPTL4 level in SSc has been assessed. However, ANGPTL4 and ANGPTL3 share numerous features, and the level of ANGPTL3 has been found to be increased in patients with SSc, and associated with the prevalence of digital ulcers, suggesting the involvement of ANGPTL3 in the pathogenesis of SSc-associated microangiopathy (30). In this regard, clarifying the role of ANGPTLs in SSc may lead to further understanding of the complex SSc pathogenesis.

Osteoclasts. Patients with SSc and pAO exhibit increased osteoclastogenesis, associated with elevated VEGF plasma levels (20). Osteoclasts are terminally differentiated cells derived from cells with a monocyte/macrophage lineage. 
Table I. HIF-regulated factors involved in angiogenesis and vascular damage in Ssc.

\begin{tabular}{|c|c|c|c|c|}
\hline Mediator & Vascular effects & Bone effects & Involvement in SSc & Refs. \\
\hline VEGF & Increased angiogenesis & $\begin{array}{l}\text { Increased osteoclastogenesis, } \\
\text { similar to M-CSF }\end{array}$ & $\begin{array}{l}\text { Increased VEGF leads to } \\
\text { defective angiogenesis. } \\
\text { VEGF165b inhibits } \\
\text { angiogenesis }\end{array}$ & $(10,17,21,31)$ \\
\hline Ang-Tie & $\begin{array}{l}\text { Ang-1/Tie } 2 \text { regulates } \\
\text { vascular quiescence. } \\
\text { Ang-2 is pro-angiogenic }\end{array}$ & Bone marrow quiescence & $\begin{array}{l}\text { Ang-1 is decreased and } \\
\text { Ang-2 elevated (in late } \\
\text { NVC patterns), with vascular } \\
\text { regression and angiostasis }\end{array}$ & $(22,25,26)$ \\
\hline $\begin{array}{l}\text { Ang-like } \\
\text { system }\end{array}$ & $\begin{array}{l}\text { Vasculoprotective, counteracts } \\
\text { VEGF vascular signaling }\end{array}$ & $\begin{array}{l}\text { ANGTPL } 4 \text { is osteoclastogenic } \\
\text { even in HIF- } 1 \alpha \text { absence }\end{array}$ & $\begin{array}{l}\text { ANGPTL } 3 \text { is increased and } \\
\text { associated with digital } \\
\text { ulcerations }\end{array}$ & (29) \\
\hline Endostatin & $\begin{array}{l}\text { Inhibits VEGF-induced } \\
\text { angiogenesis }\end{array}$ & $\begin{array}{l}\text { Inhibits osteoclastic bone } \\
\text { resorption }\end{array}$ & Marker of organ damage & $(32,33)$ \\
\hline GDF15 & $\begin{array}{l}\text { Regulates proliferation and } \\
\text { apoptosis of endothelial cells }\end{array}$ & Promotes osteoclastogenesis & $\begin{array}{l}\text { Elevated in pulmonary } \\
\text { hypertension }\end{array}$ & $(35)$ \\
\hline Wnt & $\begin{array}{l}\text { Regulates endothelial to } \\
\text { mesenchymal cell transition }\end{array}$ & $\begin{array}{l}\text { Promotes bone formation. } \\
\text { Inhibited by HIF-1 } \alpha \text { and } \\
\text { osteoblast-specific } \\
\text { transcription factor Osterix }\end{array}$ & $\begin{array}{l}\text { Wnt dysregulation is involved } \\
\text { in fibrosis. Overexpressed and } \\
\text { increased by hypoxia in } \\
\text { osteoblasts }\end{array}$ & $(36,39)$ \\
\hline Notch & $\begin{array}{l}\text { Angiogenesis and endothelial } \\
\text { function regulator }\end{array}$ & $\begin{array}{l}\text { Inhibits Wnt-induced } \\
\text { osteogenesis }\end{array}$ & $\begin{array}{l}\text { Overexpressed. Important in } \\
\text { fibrosis }\end{array}$ & $(36,39)$ \\
\hline Hedgehog & Angiogenesis regulator & Osteogenesis (upstream of Wnt) & Overexpressed & $(36,39)$ \\
\hline $\begin{array}{l}\text { TGF- } \beta / B M P \\
\text { signaling }\end{array}$ & $\begin{array}{l}\text { Regulator of angiogenesis } \\
\text { and endothelial cell-vascular } \\
\text { smooth muscle cell } \\
\text { interactions }\end{array}$ & $\begin{array}{l}\text { Critical regulatory functions in } \\
\text { osteoblast differentiation } \\
\text { and bone formation }\end{array}$ & Master regulator of fibrosis & $(37,41)$ \\
\hline
\end{tabular}

Ang, angiopoietin; ANGTPL, angiopoietin-like protein; BMP, bone morphogenetic protein; CTGF, connective tissue growth factor; GDF, growth differentiation factor; HIF, hypoxia-inducible factor; M-CSF, macrophage colony-stimulating factor; NVC, nailfold videocapillaroscopy; PDGF, platelet-derived growth factor; SSc, systemic sclerosis; TGF, transforming growth factor; VEGF, vascular endothelial growth factor.

Hypoxia acts as a major stimulator of osteoclast formation and bone resorption. The secretion of VEGF-A by hypoxic osteoclasts, regulated by RANKL-mediated activation of HIF-1 $\alpha$, is dependent on osteoclast size (31). However, osteoclasts express VEGFR1 (Flt-1) and, to some extent, VEGFR2 (Flk-1). Thus, local hypoxia could indirectly influence osteoclastogenesis via autocrine and paracrine secretion of VEGF under the control of HIF-l $\alpha$ (31). The direct role of the VEGF-VEGFR system in osteoclastogenesis and activity was demonstrated in a study of osteopetrotic mice, characterized by the absence of functional macrophage colony-stimulating factor (M-CSF) resulting in severe osteoclast deficiency (32). The results revealed that M-CSF and VEGF play almost overlapping roles in osteoclastic bone resorption Moreover, endostatin, a potent angiogenic inhibitor, also inhibits VEGF-stimulated osteoclastic bone resorption (33). In a study of patients with $\mathrm{SSc}$, endostatin was found to be increased at all stages, while angiostatin, a platelet-derived angiogenesis inhibitor, was increased only later in the disease, and was associated with osteoarticular and lung involvement (34).

Osteocytes. Osteocytes, embedded in bone matrix and isolated from vessels, act as mechanical sensors, medi- ated by hypoxia. Mechanical unloading, which may occur during advanced SSc, results in increased numbers of HIF-1 $\alpha$-expressing osteocytes (35). Hypoxic osteocytes positively regulate osteoclastic differentiation through the secretion of growth differentiation factor 15 , regulated by HIF-1 $\alpha$ (36). Hypoxia also decreases sclerostin secretion by osteocytes during bone remodeling (22). It may be hypothesized that osteocytic hypoxia and mechanical unloading may both be present in patients with SSc and severe hand involvement, contributing to $\mathrm{AO}$.

Osteoblasts. The osteoblast has a central role in the control of VEGF-mediated angiogenesis in bone. Osteoblasts express VEGF and both VEGF-A receptors, which are upregulated by hypoxia. The overexpression of HIF-1 $\alpha$ by osteoblasts leads to increased angiogenesis and osteogenesis, coupled by osteoblast-generated VEGF (37). Wnt signaling is osteogenic by promoting mesenchymal stem cell differentiation, and its inactivation leads to osteoporosis (37). Also, the endothelial-myofibroblast transition involves the canonical Wnt and Notch signaling pathways, and dysregulated Wnt signaling is involved in the pathogenesis of SSc-associated fibrosis (37). The Wnt canonical pathway is activated by 
TGF- $\beta$ (38). The involvement of Wnt in SSc-related AO is currently unclear, but HIF-1 $\alpha$ and the osteoblast-specific transcription factor Osterix in osteoblasts synergistically inhibit the Wnt pathway (39). Bone morphogenic proteins (BMPs) are modulators of the Wnt pathway, while sclerostin and dickkopf-1 are endogenous Wnt pathway antagonists $(37,40)$. Crosstalk exists between the Wnt pathway and other signaling pathways, including the Notch signaling pathway. Wnt and Notch are overexpressed in SSc $(37,38)$. Notch pathway activation inhibits Wnt-induced osteogenesis (37). Notch signaling is activated in SSc, playing an important role in fibrosis (40), but its contribution to AO is not known. However, in Hajdu-Cheney syndrome, a rare disease evolving with $\mathrm{AO}$ due to Notch2 gain-of-function mutation, osteoclast hyperactivation along with endothelial impairment are involved (41).

TGF- $\beta$ /BMP signaling has critical regulatory functions in osteoblast differentiation and bone formation, in addition to angiogenesis and endothelial cell-vascular smooth muscle cell interactions, and TGF- $\beta / \mathrm{BMP}$ signaling is the master regulator of fibrosis in SSc (42). Connective tissue growth factor (CTGF) negatively regulates BMP-2-induced signaling and osteoblast differentiation, and in SSc CTGF is profibrotic, along with TGF- $\beta$ (43).

The main hypoxia-activated participants that are possibly involved in SSc-related AO and their effects on the endothelial and bone cells are summarized in Table I.

\section{Conclusions}

In this review the critical role of the HIF-1 $\alpha /$ VEGF signaling pathway in regulating osteoclastic bone-resorption and angiogenesis is highlighted, providing evidence that increased osteoclastogenesis and higher VEGF levels may contribute to $\mathrm{AO}$ in patients with SSc. Cells of the osteoblast lineage also have important roles in angiogenic-osteogenic coupling. Although in the complex pathogenesis of $\mathrm{AO}$ osteoclast resorption appears to be the main mechanism, the impairment of osteoblastic bone formation cannot be ruled out. There are several aspects of the pathogenesis that remain unclear and require clarification, in addition to the association between calcinosis and AO. However, the research in this field might help to limit the acral changes, which contribute to the disability associated with SSc.

\section{References}

1. Allanore Y, Simms R, Distler O, Trojanowska M, Pope J, Denton CP and Varga J: Systemic sclerosis. Nat Rev Dis Primers 1: $15002,2015$.

2. Avouac J, Mogavero G, Guerini H, Drapé JL, Mathieu A, Kahan A and Allanore Y: Predictive factors of hand radiographic lesions in systemic sclerosis: A prospective study. Ann Rheum Dis 70: 630-633, 2011

3. Koutaissoff S, Vanthuyne M, Smith V, De Langhe E, Depresseux G, Westhovens R, De Keyser F, Malghem J and Houssiau FA: Hand radiological damage in systemic sclerosis: Comparison with a control group and clinical and functional correlations. Semin Arthritis Rheum 40: 455-460, 2011.

4. Lóránd V, Czirják L and Minier T: Musculoskeletal involvement in systemic sclerosis. Presse Med 43: e315-e328, 2014.

5. Avouac J, Walker U, Tyndall A, Kahan A, Matucci-Cerinic M, Allanore Y; EUSTAR, Miniati I, Muller A, Iannone F, et al: Characteristics of joint involvement and relationship with systemic inflammation in systemic sclerosis: Results from the EULAR Scleroderma trial and research group (EUSTAR) database. J Rheumatol 37: 1488-1501, 2010.
6. Johnstone EM, Hutchinson CE, Vail A, Chevance A and Herrick AL: Acro-osteolysis in systemic sclerosis is associated with digital ischaemia and severe calcinosis. Rheumatology (Oxford) 51: 2234-2238, 2012.

7. Saavedra MJ, Ambrosio C, Malcata A, Matucci-Cerinic M and Da Silva JA: Exuberant calcinosis and acroosteolysis. A diagnostic challenge. Clin Exp Rheumatol 27 (3 Suppl 54): S55-S58, 2009.

8. Freire V, Bazeli R, Elhai M, Campagna R, Pessis E, Avouac J, Allanore Y, Drapé JL and Guérini H: Hand and wrist involvement in systemic sclerosis: US features. Radiology 269: 824-830, 2013.

9. Benitha R, Modi M and Tikly M: Osteolysis of the cervical spine and mandible in systemic sclerosis: A case report with computed tomography and mgnetic resonance imaging findings. Rheumatology (Oxford) 41: 1198-1200, 2002.

10. Braun-Moscovici Y, Furst DE, Markovits D, Rozin A, Clements PJ, Nahir AM and Balbir-Gurman A: Vitamin D, parathyroid hormone, and acroosteolysis in systemic sclerosis. J Rheumatol 35: 2201-2205, 2008.

11. Schipani E, Maes C, Carmeliet G and Semenza GL: Regulation of osteogenesis-angiogenesis coupling by HIFs and VEGF J Bone Miner Res 24: 1347-1353, 2009.

12. Beyer C, Schett G, Gay S, Distler O and Distler JH: Hypoxia. Hypoxia in the pathogenesis of systemic sclerosis. Arthritis Res Ther 11: 220, 2009.

13. Ke Q and Costa M: Hypoxia-inducible factor-1 (HIF-1). Mol Pharmacol 70: 1469-1480, 2006.

14. Ivan M, Kondo K, Yang H, Kim W, Valiando J, Ohh M, Salic A, Asara JM, Lane WS and Kaelin WG Jr: HIFalpha targeted for VHL-mediated destruction by proline hydroxylation: Implications for $\mathrm{O}_{2}$ sensing. Science 292: 464-468, 2001.

15. Krock BL, Skuli N and Simon MC: Hypoxia-induced angiogenesis: Good and evil. Genes Cancer 2: 1117-1133, 2011.

16. Naldini A, Leali D, Pucci A, Morena E, Carraro F, Nico B, Ribatti D and Presta M: Cutting edge: IL-1beta mediates the proangiogenic activity of osteopontin-activated human monocytes. J Immunol 177: 4267-4270, 2006.

17. Reiseter S, Molberg Ø, Gunnarsoson R, Lund MB, Aaloken TM, Aukrust P, Ueland T, Garen T, Brunborg C, Michelsen A, et al: Association between circulating endostatin levels and vascular organ damage in systemic sclerosis and mixed connective tissue disease: An observational study. Arthritis Res Ther 17: 231, 2015.

18. Koch S, Tugues S, Li X, Gualandi L and Claesson-Welsh L: Signal tranduction by vascular endothelial growth factor receptors. Biochem J 437: 169-183, 2011.

19. Distler O, Distler JH, Scheid A, Acker T, Hirth A, Rethage J, Michel BA, Gay RE, Müller-Ladner U, Matucci-Cerinic M, et al: Uncontrolled expression of vascular endothelial growth factor and its receptors leads to inssuficient skin angiogenesis in patients with systemic sclerosis. Circ Res 95: 109-116, 2004.

20. Choi JJ, Min DJ, Cho ML, Min SY, Kim SJ, Lee SS, Park KS, Seo YI, Kim WU, Park SH and Cho CS: Elevated vascular endothelial growth factor in systemic sclerosis. J Rheumatol 30: 1529-1533, 2003.

21. Manetti M, Guiducci S, Romano E, Bellando-Randone S, Lepri G, Bruni C, Conforti ML, Ibba-Manneschi L and Matucci-Cerinic M: Increased plasma levels of the VEGF165b splice variant are associated with the severity of nailfold capillary loss in systemic sclerosis. Ann Rheum Dis 72: 1425-1427, 2013.

22. Kim I, Moon SO, Park SK, Chae SW and Koh GY: Angiopoietin-1 reduces VEGF-stimulated leukocyte adhesion to endothelial cells by reducing ICAM-1, VCAM-1, and E-selectin expression. Circ Res 89: 477-479, 2001.

23. Eklund L and Olsen BR: Tie receptors and their angiopoietin ligands are context-dependent regulators of vascular remodeling. Exp Cell Res 312: 630-641, 2006.

24. Scharpfenecker M, Fiedler U, Reiss Y and Augustin HG: The Tie-2 ligand Angiopoietin-2 destabilizes quiescent endothelium through an internal autocrine loop mechanism. J Cell Sci 118: 771-780, 2005.

25. Michalska-Jakubus M, Kowal-Bielecka O, Chodorowska G and Krasowska D: Angiopoietins-1 and -2 are differentially expressed in the sera of patients with systemic sclerosis: High angiopoietin-2 levels are associated with greater severity and higher activity of the disease. Rheumatology (Oxford) 50: 746-755, 2011.

26. Dunne JV, Keen KJ and Van Eeden SF: Circulating angiopoetin and Tie-2 levels in systemic sclerosis. Rheumatol Int 33: 475-484, 2013.

27. Santulli G: Angioprotein-like proteins: A comprehensive look. Front Endocrinol (Lausanne) 5: 4, 2014. 
28. Knowles HJ and Athanasou NA: Acute hypoxia and osteoclast activity: A balance between enhanced resorption and increased apoptosis. J Pathol 218: 256-264, 2009.

29. Swales C, Athanasou NA and Knowles HJ: Angiopoietin-like 4 is over-expressed in rheumatoid arthritis patients: Association with pathological bone resorption. PLoS One 9: e109524, 2014.

30. Ichimura Y, Asano Y, Akamata K, Aozasa N, Noda S, Taniguchi T, Toyama T, Sumida H, Sumida H, Kuwano Y, et al: Serum angiopetin-like protein 3 levels: Possible correlations with progressive skin sclerosis, digital ulcers and pulmonary vascular involvement in patients with systemic sclerosis. Acta Derm Venereol 94: 157-162, 2014

31. Utting JC, Flanagan AM, Brandao-Burch A, Orriss IR and Arnett TR: Hypoxia stimulates osteoclast formation from human peripheral blood. Cell Biochem Funct 28: 374-380, 2010.

32. Niida S, Kondo T, Hiratsuka S, Hayashi S, Amizuka N, Noda T, Ikeda K and Shibuya M: VEGF receptor 1 signaling is essential for osteoclast development and bone marrow formation in colony-stimulating factor 1-deficient mice. Proc Natl Acad Sci USA 102: 14016-14021, 2005.

33. Sipola A, Nelo K, Hautala T, Ilvesaro J and Tuukkanen J: Endostatin inhibits VEGF-A induced osteoclastic bone resorption in vitro. BMC Musculoskelet Disord 7: 56, 2006.

34. Almeida I, Olivera Gomes A, Lima M, Silva I and Vasconcelos C: Different contributions of angiostatin and endostatin in angiogensis impairment in systemic sclerosis: A cohort study. Clin Exp Rheumatol 16 Fab, 2016 (Epub ahead of print).

35. Dodd JS, Raleigh JA and Gross TS: Osteocyte hypoxia: A novel mechanotransduction pathway. Am J Physiol 277: C598-C602, 1999.
36. Hinoi E, Ochi H, Takarada T, Nakatani E, Iezaki T, Nakajima H, Fujita H, Takahata Y, Hidano S, Kobayashi T, et al: Positive regulation of osteoclastic differentiation by growth differentiation factor 15 upregulated in osteocytic cells under hypoxia. J Bone Miner Res 27: 938-949, 2012.

37. Kim JH, Liu X, Wang J, Chen X, Zhang H, Kim SH, Cui J, Li R, Zhang W, Kong Y, et al: Wnt signaling in bone formation and its therapeutic potential for bone diseases. Ther Adv Musculoskel Dis 5: 13-31, 2013.

38. Akhmetshina A, Palumbo K, Dees C, Bergmann C, Venalis P, Zerr P, Horn A, Kireva T, Beyer C, Zwerina J, et al: Activation of canonical Wnt signaling is required for TGF- $\beta$ mediated fibrosis. Nat Commun 3: 735, 2012.

39. Chen D, Li Y, Zhou Z, Wu C, Xing Y, Zou X, Tian W and Zhang C: HIF-1 $\alpha$ inhibits Wnt signaling pathway by activating Sost expression in osteoblasts. PLoS One 8: e65940, 2013.

40. Dees C, Tomcik M, Zerr P, Akhmetshina A, Horn A, Palumbo K, Beyer C, Zwerina J, Distler O, Schett G and Distler JH: Notch signaling regulates fibroblast activation and collagen release in systemic sclerosis. Ann Rheum Dis 70: 1304-1310, 2011.

41. Canalis E and Zanotti S: Hajdu-Cheney syndrome: A review. Orphanet J Rare Dis 9: 200, 2014.

42. Goumans MJ, Liu Z and ten Dijke P: TGF-beta signaling in vascular biology and dysfunction. Cell Res 19: 116-127, 2009.

43. Riccieri V, Stefanantoni K, Vasile M, Macrì V, Sciarra I, Iannace N, Alessandri C and Valesini G: Abnormal plasma levels of different angiogenic molecules are associated with different clinical manifestations in patients with systemic sclerosis. Clin Exp Rheumatol 29 (2 Suppl 65): S46-S52, 2011. 